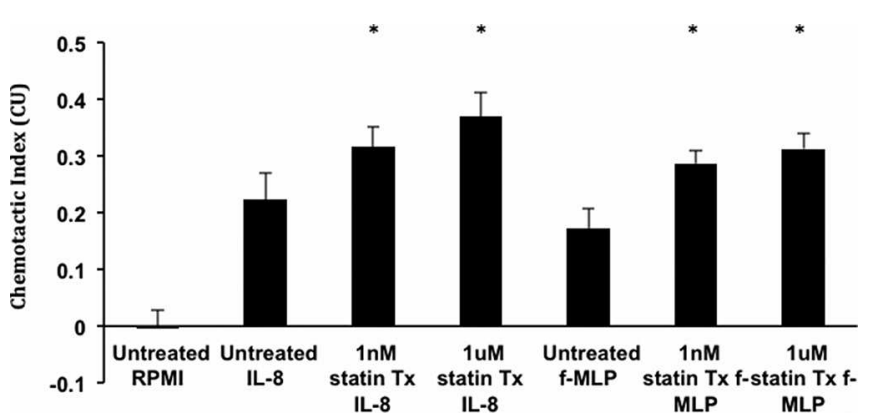

Abstract S114 Figure1 Simvastatin improves neutrophil migration in COPD. Legend. Isolated neutrophils from COPD patients $(n=13)$ migrated towards IL8 $(100 \mathrm{nM})$ or fMLP (100nM) following incubation with carrier control or Simvastatin (1nM or 1uM). Measurements were taken from 10 randomly selected cells from each individual. The average results for each subject were calculated, and an overall average was used for comparisons across groups using analysis of variance. Bars represent the mean migratory parameter with standard deviation shown as the error line. $*=$ significant difference in migratory parameter from carrier control data across groups $(p<0.05)$.

have shown neutrophil migratory accuracy to be reduced in COPD. This is thought to contribute to the destruction of lung parenchyma and the poor responses seen in infective exacerbations. We aimed to characterise neutrophil migration in COPD and assess whether physiologically relevant concentrations of simvastatin altered neutrophil migration.

Methods Neutrophils were isolated from COPD patients and healthy smoking age-matched controls (age $>60 \mathrm{yrs}, \mathrm{n}=13$ per group) and incubated with $1 \mathrm{nM}-1 \mu \mathrm{M}$ Simvastatin or with a carrier control before migratory dynamics were assessed towards IL8 and fMLP using time-lapse photography. Data is expressed as means with standard deviation in parentheses.

Results COPD neutrophils displayed reduced chemotaxis (directional speed of migration) and reduced chemotactic accuracy (Chemotactic Index - a vector analysis of migratory tracks) compared to cells from healthy age-matched controls $(\mathrm{HC})$ in the presence of IL-8 and f-MLP, replicating previous work. For example, Chemotactic Index: IL8; HC, 0.42CU (0.03), COPD $0.22 \mathrm{CU}(0.05), \mathrm{p}=0.002$ : fMLP; HC, 0.34CU (0.05), COPD, $0.18 \mathrm{CU}(0.03) \mathrm{p}=0.014)$

Treatment with Simvastatin significantly improved the chemotactic ability of COPD neutrophils in a dose response with greatest improvement seen at the highest concentration (e.g. Chemotaxis to IL8, Carrier control $0.8 \mathrm{um} / \mathrm{min}(0.2)$, $1 \mathrm{nM}$ Simvastatin $1.3 \mathrm{um} / \mathrm{min}(0.2), \mathrm{p}=0.04 ; 1 \mathrm{uM} \mathrm{Simvastatin} 1.4 \mathrm{um} / \mathrm{min}$ $(0.2), \mathrm{p}=0.004)$. A similar improvement was seen in Chemotactic Accuracy (e.g. Chemotactic Index to fMLP, Carrier control $0.17 \mathrm{CU}(0.03), 1 \mathrm{nM}$ Simvastatin $0.26 \mathrm{CU}(0.02), \mathrm{p}=0.018$; $1 \mathrm{uM}$ Simvastatin $0.31 \mathrm{CU}(0.03), \mathrm{p}=0.002)$.

Conclusions Migratory accuracy of circulating neutrophils is reduced in COPD patients compared with healthy, smoking, agematched controls but can be restored by treatment with therapeutic concentrations of Simvastatin in vitro. Our data suggest statin therapy might be an adjuvant intervention in COPD, modulating neutrophil responses.

\section{S115 THE EFFECTS OF HYPOXIA ON NEUTROPHIL-MEDIATED TISSUE DAMAGE IN THE LUNG}

${ }^{1} \mathrm{~K}$ Hoenderdos, ${ }^{2} \mathrm{RA}$ Hirst, ${ }^{1} \mathrm{~L}$ Porter, ${ }^{1} \mathrm{C}$ Chen, ${ }^{1} \mathrm{~K}$ Lodge, ${ }^{3} \mathrm{C}$ O'Callaghan, ${ }^{1} \mathrm{ER}$ Chilvers, ${ }^{1} \mathrm{AM}$ Condliffe; ${ }^{1}$ University of Cambride, Cambridge, Cambridgeshire; ${ }^{2}$ University of Leicester, Leicester, Leicestershire; ${ }^{3}$ University College London, London, London

10.1136/thoraxjnl-2013-204457.122
Sites of infection and inflammation are profoundly hypoxic, requiring neutrophils to function under low oxygen tensions. Although neutrophils are well adapted and can rely on glycolytic metabolism, hypoxia still impairs the neutrophil oxidative burst, reduces bacterial killing and delays apoptosis. ${ }^{1}$ As neutrophil proteases have been implicated in lung diseases such as COPD, we hypothesised that hypoxia might also promote neutrophil degranulation, with an enhanced potential for neutrophil-mediated tissue injury.

Neutrophils isolated from healthy volunteers were subjected to normoxia $(20 \mathrm{kPa})$ or hypoxia $(3 \mathrm{kPa})$ and subsequently activated with GM-CSF $(10 \mathrm{ng} / \mathrm{ml})$ and the bacterial tri-peptide fMLP $(100 \mathrm{nM})$. A549 cells and ciliated human primary bronchial epithelial (NHBE) cells were exposed to neutrophil supernatants, the extent of cellular damage was determined by MTT assay (A549 cells), EM ultrastructure and cleaved caspase 3 staining. Ciliary function was also investigated using video microscopy in the ciliated NHBE cells.

Hypoxic incubation for 4 hours resulted in a 3-5 fold increase in neutrophil degranulation; this was evident for active elastase, MPO, MMP-9 and lactoferrin and hence occurred from all granule sub-types. Supernatants from hypoxic neutrophils induced 50\% more cell death in A549 cells compared to supernatants from normoxic neutrophils. NHBE cells exposed to supernatants from hypoxic versus normoxic neutrophils suffered more cellular damage (EM; images were scored for cytoplasmic blebbing, vacuole formation and dead cells), an increase in LDH activity (from $35.7 \pm 6$ to $50.2 \pm 0.7 \mathrm{nmol} / \mathrm{min} / \mathrm{ml}$, was indicative of cell death), increased cleaved caspase 3 staining was shown to be an indicator of apoptosis and there was a substantial increase in the proportion of dyskinetic and immotile cilia.

In conclusion; hypoxia induced a destructive neutrophil phenotype with delayed apoptosis, impaired bacterial killing and increased release of histo-cytotoxic proteases. This phenotype may be important for understanding the mechanisms of chronic inflammatory diseases like COPD.

Funded by the British Lung Foundation and NIHR Cambridge BRC.

\section{REFERENCES}

1. McGovern, N. N. et al. Hypoxia selectively inhibits respiratory burst activity and killing of Staphylococcus aureus in human neutrophils. J. Immunol. Baltim. Md 1950 $186,453-463$ (2011).

\section{Physiological measurement of breathlessness and breathing}

\section{S116 BREATHLESSNESS IN COPD IS ASSOCIATED WITH ALTERED COGNITIVE PROCESSING IN THE MEDIAL PREFRONTAL CORTEX}

M Herigstad, A Hayen, E Evans, R Davies, M Hardinge, K Wiech, KT Pattinson; University of Oxford, Oxford, UK

\subsection{6/thoraxjnl-2013-204457.123}

Introduction Breathlessness is the main cause of suffering in COPD. Its brain mechanisms remain poorly understood, yet may represent a novel therapeutic avenue. Until now, functional magnetic resonance imaging (FMRI) studies of breathlessness have been limited to experiments in healthy volunteers. FMRI demonstrates that imagination of painful events engages the same brain networks responsible for perception of physical pain. We 
adapted this technique to identify brain areas responsible for breathlessness perception in COPD. We hypothesised that healthy controls would demonstrate brain patterns similar to that observed in previous FMRI studies in healthy volunteers. As psychological dysfunction is strongly associated with COPD we hypothesised that patients would show greater engagement of cognitive brain areas.

Methods 44 COPD patients and 40 matched controls undertook FMRI scanning (Siemens 3T), and psychological and physiological assessments. During scanning, participants were presented with previously validated breathlessness-related word cues and rated breathlessness on a visual analogue scale. FMRI analysis was performed with FSL (http://www.fmrib.ox.ac.uk/fsl). Significant activations were determined as $\mathrm{Z}>2.3$, with a cluster probability threshold of $\mathrm{P}<0.05$, corrected for multiple comparisons.

A modified shuttle walk test (MSWT) and spirometry were performed. The following questionnaires were administered: Center for Epidemiological Studies Depression Scale, Dyspnoea12, State and Trait Anxiety Inventory, bespoke catastrophising and vigilance questionnaires, Fatigue Severity Scale and St Georges Respiratory Questionnaire.

Results Imaging and questionnaire results are displayed in the figure. MSWT values (mean \pm SD) were $331+/-193$ m (patients) and $804+/-274 \mathrm{~m}$ (controls) ( $\mathrm{p}<0.001)$. FEV1 (\% predicted) was $0.6 \pm 02$ (patients) and $1.0 \pm 0.2$ (controls) $(\mathrm{p}<0.001)$

Conclusions We observed differing brain activation patterns in response to dyspnoea-related word cues between COPD patients and controls. The control group displayed a similar activation pattern to that observed in previous FMRI studies of breathlessness in healthy volunteers while COPD patients display significantly greater activation in the medial prefrontal cortex (emotion control and memory consolidation). Our behavioural data demonstrates greater psychomorbidity in patients. Taking our imaging and behavioural findings together, we propose that in COPD engagement of the medial prefrontal cortex distorts the processing of breathlessness sensations towards greater reliance on fear memories and expectations, contributing to a vicious circle of avoidance and fear.

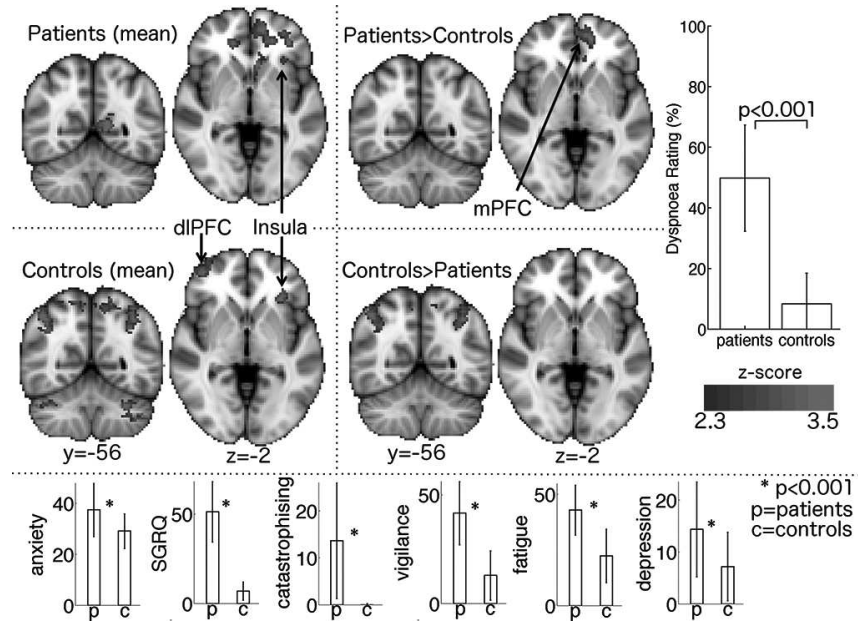

Abstract S116 Figure 1.

\section{S117 FACTORS DRIVING THE DEVELOPMENT OF CHRONIC RESPIRATORY FAILURE IN OBESE PATIENTS}

${ }^{1} \mathrm{~A}$ Manuel, ${ }^{2} \mathrm{~N}$ Hart, ${ }^{1} \mathrm{JR}$ Stradling; 'Oxford Unit for Sleep and Respiratory Medicine, Oxford, Uk; '2 Lane Fox Unit, St Thomas' Hospital, London, Uk

10.1136/thoraxjn-2013-204457.124
Introduction Currently, there are limited data reporting the pathophysiology of chronic respiratory failure in obese patients, the so called Obesity Hypoventilation Syndrome (OHS). Although a number of hypotheses have been proposed, there are no comprehensive data that have investigated the imbalance between respiratory muscle load, capacity and drive. We aimed to investigate the factors contributing to early chronic respiratory failure in obese patients including body habitus, upper airways obstruction, lower airflow obstruction and lung volume.

Methods A cross sectional study was performed in an obese group of subjects (BMI $>30 \mathrm{~kg} / \mathrm{m}^{2}$ ) with and without early chronic respiratory failure. Early chronic respiratory failure was arbitrarily defined for this analysis as an arterial base excess $>2$ $\mathrm{mmol} / \mathrm{l}$ as this is a metabolic respiratory biomarker of 24 -hour carbon dioxide levels. Arterial blood gas measurements were undertaken in the morning, after an overnight study to determine the $4 \%$ oxygen desaturation index and apnoeas hypopnoea index. An overnight auto titrating continuous positive airway pressure study (S9 ResMed, Oxfordshire, UK) was used as another measure of the severity of upper airways loading. Pulmonary function and the forced oscillation technique (MS-IOS, CareFusion, CA, USA) to measure of airway impedance were performed in the upright and supine position.

Abstract S117 Table 1. Anthropometric and physiological characteristics of the patients without and with evidence of a metabolic compensation for increased $\mathrm{CO}_{2}$ levels.

\begin{tabular}{|c|c|c|c|c|}
\hline & \multicolumn{2}{|c|}{$\begin{array}{l}\text { Base excess } \\
\leq 2 \mathrm{mmol} / \mathrm{l} \\
(\mathrm{n}=22)\end{array}$} & \multicolumn{2}{|c|}{$\begin{array}{l}\text { Base excess } \\
>2 \mathrm{mmol} / \mathrm{l} \\
(\mathrm{n}=32)\end{array}$} \\
\hline & Mean & $\begin{array}{l}\text { Standard } \\
\text { deviation }\end{array}$ & Mean & $\begin{array}{l}\text { Standard } \\
\text { deviation }\end{array}$ \\
\hline BMI $\left(\mathrm{kg} / \mathrm{m}^{2}\right)$ & 44.6 & 9.8 & 48.3 & 9.64 \\
\hline Epworth Sleepiness Score (ESS) & 12.3 & 5.45 & 12.8 & 5.28 \\
\hline $\mathrm{PaCO}_{2}(\mathrm{kPa})$ & 5.05 & 0.5 & 5.94 & 1.6 \\
\hline $\mathrm{HCO}_{3}{ }^{-}(\mathrm{mmol} / \mathrm{l})$ & 24.6 & 1.2 & 27.7 & 1.6 \\
\hline Base excess (mmol/l) & 0.27 & 1.3 & 3.8 & 1.8 \\
\hline $\begin{array}{l}\text { Oxygen Desaturation Index } \\
\text { (ODI; events/hr) }\end{array}$ & 40.4 & 27.5 & 51.0 & 40.1 \\
\hline $\begin{array}{l}\text { Apnoea-Hypnoea Index } \\
\text { (AHI; events/hr) }\end{array}$ & 24.7 & 29.1 & 30.1 & 29.3 \\
\hline $\begin{array}{l}\text { Mean oxygen saturations }\left(\mathrm{SpO}_{2}\right) \\
\text { overnight (\%) }\end{array}$ & 89.3 & 1.7 & 89.1 & 6.9 \\
\hline AutoCPAP pressure $\left(\mathrm{cmH}_{2} \mathrm{O}\right)$ & 12.4 & 2.4 & 12.4 & 2.8 \\
\hline Upright FEV $1 \%$ predicted & 107.2 & 22.1 & 91.5 & 19.2 \\
\hline Upright FVC \% predicted & 107.4 & 23.0 & 95.5 & 17.4 \\
\hline Supine $\mathrm{FEV}_{1} \%$ predicted & 89.7 & 21.3 & 77.4 & 18.5 \\
\hline Supine FVC $\%$ predicted & 92.2 & 21.3 & 80.2 & 22.0 \\
\hline $\begin{array}{l}\text { Upright Expiratory reserve } \\
\text { volume (ERV) (mls) }\end{array}$ & 534 & 360 & 497 & 290 \\
\hline Supine ERV (mls) & 187 & 166 & 152 & 187 \\
\hline $\begin{array}{l}\text { Upright Airway Impedance } \\
\text { at FRC }(\mathrm{mmHg} / \mathrm{l} / \mathrm{s})\end{array}$ & 0.55 & 0.38 & 0.83 & 0.66 \\
\hline $\begin{array}{l}\text { Supine Airway Impedance at } \\
\text { FRC (mmHg/l/s) }\end{array}$ & 1.44 & 0.73 & 1.68 & 0.84 \\
\hline
\end{tabular}

Results 54 patients, aged $51.9 \pm 9.08$ years, were recruited with BMI of $46.4 \pm 9.53$.

Conclusion We are finding considerable heterogeneity in terms of anthropometric and physiological findings within obese subjects with and without early chronic respiratory failure. We have shown that subjects with early chronic respiratory failure, 